\title{
Strategies for the selection of reference organisms in environmental assessment programmes
}

\author{
S. Sundell-Bergman and L. Moberg
}

Swedish Radiation Protection Institute, 17116 Stockholm, Sweden

\begin{abstract}
At present there exists no internationally accepted strategy for the protection of the enviroument against ionising radiation although the requirement is increasing due to both growing public concern for environmental protection issues and to the evolving integration of environmental impact assessments into the regulatory process. In order to progress the work, strategies have been formulated which include the use of reference organisms. This approach resembles the concept of reference man, which has been used in traditional radiation protection for many years. The purpose of selecting reference organisms is to narrow the problem and simplify the development of appropriate exposure and dose models in the areas of environmental radiation protection. These ideas will be further explored in an ongoing EU-financed project (FASSET: Framework for Assessment of Environmental Impact) aiming at developing a system for protection of the environment. The selection of reference organisms is based on criteria which relate to both ecological and radiation sensitivities as well as exposure. Not all of the different identified effect wariables will be predominant at the same time and consequently some kind of judgements needs to be done. If applicable, multivariate analysis may show the most influential variables and also existing interactions between these variables
\end{abstract}

\section{INTRODUCTION}

In current regulatory practice concern for protection of the environment from potential adverse effects of radiation exposure has typically been addressed through reliance on the assumption that protection of humans will result in adequate protection of the environment [1]. This standpoint has been challenged in recent years and work is in progress to explicitly develop protection criteria for the environment $[2,3]$.

Recently, within its fifth framework programme, EU has launched a project, FASSET [4], aiming at developing a methodology to be used for environmental risk assessments after exposure to ionising radiation. The main objective of the project is to create a system which links together exposures, radiation doses and effects. Although the project addresses many important environmental issues associated with routine releases and radioactive waste management, it needs to be limited to sets of exposure scenarios and dose models for reference organisms. Pentreath and Woodhead [5] have previously introduced the concept of reference organisms as a stylised approach to be used for assessment of detrimental environmental effects after radioactive contaminations. The rationale of the reference organism approach is that a few carefully selected organisms should help to assess the exposures and dosses for the biota following radioactive contamination. Reference organisms should also be used as indicators of the degree of biological effects that could be expected in a radioactive contaminated environment. Moreover, it is desirable for validation purposes that they refer to organisms sufficiently abundant and for which changes in known characteristics can be easily measured. The identified organisms could thereby prove useful in environmental surveillance programs. From the gathered information on doses, exposures and effects of reference organisms, conclusions on the fitness for other species or the environment as a whole could eventually be drawn.

The choice of reference organisms is a crucial step in the risk assessment, thereby emphasising the importance to clarify the objective of each assessment condition. Since the variability of species and environmental characteristics between regions is often marked, it seems logical that reference organisms in practice are tools for specific rather than generalized applications. Several criteria for the selection of species have been put forward withholding many variables [4]. Due to the large number of factors of 
varying importance, where also interactions and correlations between these factors are anticipated, the selection of reference organisms could preferably be based on a multivariate strategy [6].

\section{REFERENCE ORGANISM - THE CONCEPT}

The stylised approach of reference methodology has proven to be useful in various situations. ICRP introduced the concept of reference man many years ago, to be used in radiation protection for dose estimations [7]. By using this approach more exactitude in the dose determinations was achieved thus facilitating the comparison and judgement of doses.

For assessment of long-term safety of radioactive waste disposals the concept of reference biosphere has been developed in the BIOMASS project, established under the auspices of the IAEA [8]. This methodology provides a formal procedure for the improvement of assessment biospheres in the estimation of long-term effects. The strategy is based on a staged approach where some overall requirements have been defined for each stage [9].

In order to provide guidance for realistic radiation dose assessments to the general public from nuclear installations within EU, a study is going on to assign a suitable methodology for that purpose. This methodology will involve identifications of reference groups of the population for radiation dose assessment in conformity with the critical group concept of ICRP [1].

In accordance with the above-mentioned concepts, reference organisms could be applied in radiation protection to estimate doses to organisms in the environment. Due to its complexity, a variety of organisms must be identified in order to serve the same purpose as for example the reference man, and the classification requires good knowledge of ecological, radioecological and radiobiological characteristics regarding the presumptive reference organism. The selection of a number of representative organisms must also aim at covering the total spread of different responses due to the induced stimuli.

\section{KEY ISSUES}

Ecological sensitivity is a fundamental parameter for the assessment of potential environmental impacts [10]. An important property of ecological sensitivily is the hierarchical structure, with each level nested on the previous level. Ecological effects, due to both biotic and abiotic factors, are usually considered at the population or other higher levels of organisation although mediated through the responses of individual organisms [11]. Examples of factors influencing the population densities are fitness and food supply including parasitism, predation, herbivore, competition and climate. It has become increasingly apparent that many of these factors interact and will indirectly affect the population dynamics [12]. Some species, keystone species, have an effect out of all proportion to their commonness or biomass in an ecological community and cause serious consequences for the inhabitants upon removal. Predators, prey and habitat engineers usually belong to the keystone species list. A Red List is a catalogue of species whose survival is uncertain and this list of endangered and threatened species constitutes an important basis for making priorities with regard to conservation and management [13].

Radioactive contamination will affect the population by acute (lethality) and late effects (genetic diversity), the community by biological diversity and the whole ecosystem through the flow of nutrients but when effects are observed the hazard has already occurred for several individuals. Biomarkers, which refer to cellular and molecular changes occurring at the individual level, may be related to ecologically relevant parameters such as survival, growth, and reproduction [14].

Radiation sensitivity is of concem for the choice of reference organisms also when they are selected on generic basis. Endpoints need to be defined which are related to the radiation harm in the environment and which could be easily estimated. The energy imparted by decay of radionuclides in living organisms will cause a variety of effects. It is well known that ionising radiation induce damages at a molecular level, which is subsequently expressed at higher levels of an organism [15]. Molecular 
damages may be repaired and the cellular systems restored to their normal functional state but damages to DNA may also lead to acute lethality or mutations. The understanding of mechanisms of radiotoxicity has a great potential as a means of identifying sensitive organisms and to predict their response to radiation. The dose response relationships for various endpoints in the low-dose region are mainly non-existing and this has to be remembered in the strategy for selection of suitable species.

Reproductive success, i. e. effects on fertility and fecundity, has been stated as the most important end-point for environmental radiation protection [16]. Mutations, generally induced at lower doses, may only become critical for larger mammals or birds whose populations are at minimal sizes and which unlike other biota in the ecosystem do not have a large reproductive surplus as a reproductive strategy.

The effectiveness of radiation for the end-points of concern has to be estimated based on dosimetry. In similarity to the situation for humans severat weighting factors are conceivable in order to fill the role for the biota equivalent to the radiation and tissue weighting factors for man [1]. The suggestion is to introduce three new factors dealing with exposure and sensitivity, namely

- a radiobiological weighting factor comprising radiation sensitivities

- an ecological weighting factor covering important ecological effects such as reproductive capacities and strategies

- a radioecological weighting factor which include migration and transfer of radionuclides, ecological half-lives, etc.

It can not be excluded that combinations of modest radiation sensitivity and ecological parameters may have effects on the population of organisms. Therefore, it seems appropriate to define ecological radiosensitivity, as an important parameter for the selection process. The objective of this parameter would be to quantitatively combine radiation and ecological effects in view of risk assessments.

\section{THE SELECTION PROCESS - AN EXAMPLE}

The identified criteria for reference organisms could be arranged in a stepwise manner, where each step introduces further details to the selection process. The selected organisms must not fulfil all the identified criteria in its entirety but the strength of the organisms must outweigh the weaknesses that need to be considered in an applied situation [17].

The overall criterion for choosing reference organisms is clearly formulated goals (the assessment context) since the results should be used to answer or provide information relating to specific questions. The first step in the selection process addresses the basic information needed for determination of reference organisms. Principally this step includes:

- the type of exposure

- the type of ecosystems (at the site)

- the time frame in the assessments

- the biological end-point of concem for the assessment

- societal demands.

The following steps in the selection process are aimed to provide increasing and sufficient details to select the organisms to be considered in the assessment and to justify this selection for the estimates of exposure and dose. By systematically going through the list the main characteristics of a reference organism may be defined. All exclusions/choices made in this process must be clear and documented. However, the availability of quantitative data for the various steps is fragmentary and in many cases expert judgements must be performed to compensate for missing data. 
Table 1 outlines one example of the stepwise procedure that could be followed in the selection process. Obviously, steps 2 and 3 will generate much data about the organisms that must be handled in a rationale way by setting up various matrices. In addition the numerous interactions between many of the variables need to be judged in a systematic and transparent way. The advantages with this approach are straightforwardness and fairly simple performance. The shortcomings are the difficulties to obtain a general view and to detect groupings, similarities and dissimilarities between different organisms. There are also a possibility that properties are ignored in one step which may be of great importance for the following steps. Ultimately this will certainly lead to the identification of a higher number of organisms than necessary for the purpose of the assessment. The process is also time-consuming, thus limiting its usefulness.

Table 1. A schematic illustration of a stepwise manner for the selection of representative organisms showing some tentative criteria.

\begin{tabular}{|c|c|c|c|c|c|}
\hline Step 0 & \multicolumn{5}{|c|}{ Goal/Purpose (assessment context) } \\
\hline & Exposures & Doses & Etfects & Time frame & \begin{tabular}{|l|}
$\begin{array}{l}\text { Societal } \\
\text { demands }\end{array}$ \\
\end{tabular} \\
\hline Step 1 & $\begin{array}{l}\text { Radionuclides } \\
\text { Type of } \\
\text { ecosystem } \\
\text { Geographic } \\
\text { localisation } \\
\end{array}$ & $\begin{array}{l}\text { Type of } \\
\text { exposure }\end{array}$ & $\begin{array}{l}\text { Radiation } \\
\text { sensitivity } \\
\text { (ecosystem) } \\
\text { Taxonomy }\end{array}$ & $\begin{array}{l}\text { Prospective } \\
\text { Retrospective }\end{array}$ & $\begin{array}{l}\text { Socio-economic } \\
\text { consideration } \\
\text { Prediction of } \\
\text { changes }\end{array}$ \\
\hline Step 2 & $\begin{array}{l}\text { Migration of } \\
\text { radionuclides } \\
\text { Uptake } \\
\text { Accumulation } \\
\text { Lateral } \\
\text { (re)distribution }\end{array}$ & $\begin{array}{l}\text { Habitat } \\
\text { Metabolism } \\
\text { External } \\
\text { irradiation }\end{array}$ & $\begin{array}{l}\text { Ecological } \\
\text { sensitivity } \\
\text { Hierarchical } \\
\text { order } \\
\text { Ecological } \\
\text { relevance } \\
\text { Inventory } \\
\end{array}$ & Longevity & $\begin{array}{l}\text { Philosophical } \\
\text { matters }\end{array}$ \\
\hline Step 3 & $\begin{array}{l}\text { Ecological half- } \\
\text { lives } \\
\text { Function } \\
\text { Intertaces } \\
\text { Resilience } \\
\text { Abundance }\end{array}$ & $\begin{array}{l}\text { Size } \\
\text { Geometry } \\
\text { (organism) } \\
\text { Radiation } \\
\text { environment }\end{array}$ & $\begin{array}{l}\text { Sex } \\
\text { Age structure } \\
\text { Dispersal } \\
\text { capabilities }\end{array}$ & Life cycle & $\begin{array}{l}\text { Public acceptance } \\
\text { Documentation }\end{array}$ \\
\hline Step 4 & \multicolumn{5}{|c|}{$\begin{array}{l}\text { Product: A set of matrices, each one characterizing a possible reference organism. } \\
\text { Alternatively, one matrix for dose and all reference organisms, one for effects and all } \\
\text { reference organisms, one for sensitivity and all reference organisms etc. }\end{array}$} \\
\hline
\end{tabular}

\section{A MULTIVARIATE APPROACH FOR DATA PROCESSING}

In order to cope with the occurrence of interacting and correlated variables, multivariate analysis could be applied as a structured altemative for selecting the relevant organisms. Multivariate analysis provides tools for general overviews, classification and modelling [5]. In many situations the most interesting information is often obtained from a combination of dependencies of several variables and not from the 
amount of data. To optimise the information received from these dependencies demands multivariable projection methods.

Principal component analysis is a method frequently used for data description and explorative data structure modelling of any generic data matrix [17]. Additionally, regression methods could be applied for determination and ranking of correlated variables in a selection process. From established data matrices, models are generated by a software, for example The Unscramblerß [18], that can be used for quantifications and predictions.

In the bi-linear case two matrices are designed, one consisting of controlled variables (e.g. exposure) and the other containing the responses (e.g. radiation sensitivity). The multivariate analysis will indicate the need for a further split of the originally designed two matrices into three or more in order not to obscure existing correlation pattems by performing bi-linear analysis on a $\mathrm{N}$-linear problem. The structured database, which is going to be developed within the FASSET project [4], could serve as a basis for creating these matrices.

The controlled variables contain factors that have impact on the responses of concern, such as activity concentrations, doses, dose rates, types of radiation, size, sex ratio, age structure, longevity, habitat, position in the food chain (food webs), climate (abiotic factors), dispersion capabilities and abundance.

The response variables for each organism are related to exposition and ecological and radiation sensitivity. The effects of radiation could be split into four major categories such as morbidity, mortality, reproduction disturbances and genotoxic effects (mutations). The latent periods needs also to be included since the time span between exposure and the appearance of biological effects is an important parameter for the assessments.

A complimentary result from the multivariate analysis would be to obtain numerical values for the suggested weighting factors and information about important variables for the respective factor. However, the basic assumption underlying the use of multivariate analysis is that the data carries information about what is desirable to know. If the collected data does not contain relevant information, multivariate methods will not be of any help in selecting reference organisms as indicators but that would also be difficult to accomplish with any other method.

\section{Acknowledgements}

The authors wish to thank R. Bergman (Pharmacia, Uppsala), R. Bergman (FOI, Umeå) and K.J. Johanson (SLU, Uppsala) for their contributions and valuable advice. The work was supported by and forms part of the EC $5^{\text {th }}$ Framework Rescarch Project FASSET , contract FIGE-CT-2000-00102

\section{References}

1. Annals of the ICRP: ICRP Publication 60, 1990 Recommendations of the International Commission on Radiological Protection (1991).

2. IAEA, Protection of the environment from the effects of ionising radiation; a report for discussion. IAEA-TECDOC-1091, Vienna (1999).

3. P. Strand, J.E. Brown, D.S. Woodhead, C-M Larsson, in Proceedings of $10^{\text {th }}$ International Congress on Radiation Protection (IRPA), May 2000, Hiroshima, 2000; P-2a-1 16.

4. FASSET, Framework for Assessment of Environmental Impact, A project within the EC $5^{\text {th }}$ Framework Programme (2000).

5. R.J. Pentreath, D.S. Woodhead, Science Total Env. (in press).

6. K.H. Esbensen, in Multivariate Analysis - in practice, $4^{\text {th }}$ edn. (CAMO ASA, 2000)

7. ICRP 23, Report of the Task Group on Reference Man (1974)

8. IAEA, Alternative Assessment Contexts: Implications for the development of Reference Biospheres and Biosphere Modelling. BIOMASS Themel, Working Doc. No 6 (1999)

9. I.G. Crossland, C. Torres-Vidal, Biospheres for long term safety assessment of radioactive waste disposal (1999) 
10. E.P. Odum, in Fundamentals of Ecology (Saunders, Philadelphia, 1971).

11. P. Stiling, in Ecology - Theories and Applications, edited by T. Ryu, $3^{\text {rd }}$ edn. (Prentice Hall, Upper Saddler River, New Jersey, 1999)

12. P. Stiling, A.M. Rossi, Ecology 78 (1997).

13. The 2000 Red list of Swedish species, edited by U. Gärdenfors (Artdatabanken, SLU, Uppsala, 2000)

14. A.L. Brooks, Int. J. Radiat. Biol. 75 (1999)

15. Sources and effects of radiation, Report of the United Nations Scientific Committee on the effects of atomic radiation Volume II Effects (2000)

16. K.J. Johanson, in Radioecology, edited by E.Holm (World Scientific, Singapore 1994)

17. S. Wold, Technometrics 20 (1978)

18. The Unscrambler, www.camo.no. 